\title{
CORPUS Corpus
}

Archivos virtuales de la alteridad americana

Vol 5, No 2 2015

Julio / Diciembre 2015

\section{Presentación del debate: Producción de conocimientos e interdisciplina. Arqueología, antropología e historia.}

Roxana Boixadós and Norma Ratto

\section{OpenEdition}

\section{Journals}

Electronic version

URL: http://journals.openedition.org/corpusarchivos/1499

DOI: 10.4000/corpusarchivos. 1499

ISSN: 1853-8037

Publisher

Diego Escolar

\section{Electronic reference}

Roxana Boixadós y Norma Ratto, «Presentación del debate: Producción de conocimientos e interdisciplina. Arqueología, antropología e historia. », Corpus [En línea], Vol 5, No 2 | 2015, Publicado el 19 diciembre 2015, consultado el 11 mayo 2019. URL : http://journals.openedition.org/ corpusarchivos/1499; DOI : 10.4000/corpusarchivos.1499

This text was automatically generated on 11 May 2019 


\title{
Presentación del debate: Producción de conocimientos e interdisciplina. Arqueología, antropología e historia.
}

\author{
Roxana Boixadós and Norma Ratto
}

1 En la década del 70 del siglo pasado, John Murra presentaba en los medios académicos el modelo de Control vertical de un máximo de pisos ecológicos, síntesis elaborada a partir de la experiencia de trabajo interdisciplinaria del autor $-\mathrm{y}$ con otros especialistas- en etnología, historia y arqueología sobre las sociedades indígenas y campesinas del mundo andino. ${ }^{1} \mathrm{El}$ modelo invitaba a comprobar y poner a prueba los alcances y la persistencia de las prácticas andinas de control de recursos que se postulaba habían caracterizado las relaciones entre las sociedades locales y el medio ambiente en dos dimensiones complementarias: por un lado, a través de observaciones directas realizadas durante jornadas de trabajos de campo en diferentes zonas ecológicas, orientadas por la transmisión de saberes de los campesinos, y por otro, recurriendo a fuentes de importante profundidad temporal, testimonios reveladores - en variabilidad de formatos - de las transformaciones coloniales. En este mismo registro Murra incluía los resultados de las investigaciones arqueológicas que permitían por entonces replantear las políticas de control de recursos y movilización de la población campesina llevados adelante por el Tawantinsuyu, una apropiación del espacio andino a gran escala que articulaba con prácticas enraizadas en un pasado lejano. Los resultados y avances de las investigaciones arqueológicas desafiaban igualmente la interpretación de crónicas y fuentes administrativas y las versiones tradicionales históricamente consolidadas.

2 La interdisciplina se planteaba ya entonces no solo como un marco de asociación y colaboración entre especialistas de distinta formación académica sino también como parte de una estrategia de trabajo colectiva que orientaba la búsqueda de evidencias materiales y su interpretación, la relectura de fuentes y la resignificación de las prácticas en el presente etnográfico hacia intereses comunes. En suma, la interrelación estrecha 
promovía procesos de construcción de conocimientos dinámicos sobre bases empíricas cada vez más diversas, en permanente consulta, interacción y debate, bajo la aspiración de alcanzar bases más sólidas y generar avances sustantivos.

Desde entonces, la práctica interdisciplinaria ha sido observada, continuada o criticada por enfoques que buscaron problematizar $-\mathrm{y}$ sobre todo afinar- métodos y técnicas específicas de análisis según las disciplinas. La arqueología, a la par que ha profundizado la interrelación con métodos y técnicas de otras disciplinas (naturales y físico-químicas) en pos de alcanzar análisis más precisos, ha renovado y diversificado su quehacer recurriendo cada vez más a la articulación con fuentes escritas, a la memoria de los pobladores y comunidades donde se sitúan los escenarios de trabajo y a la revisión de los materiales de campo producidos por investigadores pioneros. El pasado interrogado desde el presente descubre múltiples pliegues y mediaciones, y también reconoce procesos de resignificación constante. Así, la producción más reciente relativa a las sociedades agroalfareras del período prehispánico y de los primeros siglos de la conquista muestra una creciente tendencia a la diversificación de estrategias de trabajo; ciertos temas y problemas demandan una pluralidad de enfoques para ser abordados de manera adecuada, lo que conlleva frecuentes tensiones tanto en la dimensión teórica como en la metodológica.

Sobre esta base de constataciones generales, pero ancladas en preocupaciones renovadas en torno a cómo articular y validar procesos de construcción de conocimientos basados en cruces de matrices y prácticas interdisciplinarias, preparamos una propuesta que consiste en recuperar las experiencias de trabajo arqueológico que reconocen apropiaciones del trabajo de campo antropológico y de recursos archivísticos.

Invitamos a cinco colegas con tradición de trabajo en arqueología del Noroeste y Centro del país -José María Vaquer, Norma Ratto, Sebastián Pastor, Laura López y Laura Quiroga - a un encuentro para intercambiar y debatir ideas, experiencias, reflexiones y preguntas en torno a tres temas:

6 a) arqueología y trabajo de campo: relaciones del especialista con el medio local; de qué manera articulan con la investigación arqueológica o la obstaculizan; entrevistas, memorias y observaciones, cómo se integran estos contextos de producción en la elaboración de resultados y/o la formulación de proyectos específicos.

b) arqueología e historia: los usos del pasado en un doble registro. Por un lado, con los trabajos de la etapa precientífica (siglo XIX y comienzos del XX; libretas de campo, colecciones de museos, informaciones de diarios locales, primeros trabajos de investigación, de qué manera -y bajo qué recaudos- pueden ser tratados como fuentes. Por otro, documentación de etapas colonial y republicana, qué datos o indicios aportan y cómo se los problematiza.

c) la experiencia de las prácticas interdisciplinarias, personales o colectivas, cuáles son los aportes específicos en torno a determinados problemas y qué limitaciones conllevan.

Los autores presentaron sus aportes en el encuentro que tuvo lugar en la Sala de Investigadores del Instituto de Historia Argentina y Americana Dr. E. Ravignani; luego Ana María Lorandi y Verónica Williams expusieron sus comentarios y finalmente se abrió un tiempo para la participación del público, preguntas a los autores y respuestas, y para el intercambio de ideas. El cierre recoge algunos de los temas que se trataron en ese espacio junto con las reflexiones de las organizadoras de este encuentro. 


\section{NOTES}

1. Murra, John 1975. "El control vertical de un máximo de pisos ecológicos en la economía de las sociedades andinas". Formaciones Económicas del Mundo Andino. Lima: Instituto de Estudios Peruanos.

\section{AUTHORS}

\section{ROXANA BOIXADÓS}

Universidad de Buenos Aires, Universidad Nacional de Quilmes, Consejo Nacional de Investigaciones Científicas y Técnicas, Argentina

Correo electrónico: roxboixados@gmail.com

\section{NORMA RATTO}

Museo Etnográfico Juan B. Ambrosetti, Facultad de Filosofía y Letras, Universidad de Buenos Aires

Correo electrónico: nratto@filo.uba.ar 